\title{
Preparing nurses for fieldwork in tropical nursing
}

BY ALEXIS SCHMID, DNP, RN, CPNP-PC/AC, CPEN, CCRN, DTN AND FRANCES WOOD, RN, RCM, HV Cert, BSc, PGCE, PGCert

Abstract: Due to factors related to increasing globalization, geopolitical conflicts, and climate change, tropical nursing is increasingly important. This article offers an overview of the Diploma in Tropical Nursing program and explores the challenges facing nurses who serve patients in tropical settings with limited resources.

Keywords: DTN, tropical nursing, diploma in tropical nursing, education

TROPICAL NURSING IS a complex and difficult concept to define due to the rapidly changing context and conditions of nursing practice related to increasing globalization, geopolitical conflicts, and climate change. It must be viewed through a global lens and encompass the interdependent relationships between nations with diverse social, cultural, economic, and environmental needs. ${ }^{1}$ This article explores the challenges facing nurses in tropical areas with limited resources and offers an overview of the Diploma in Tropical Nursing (DTN) program, which is designed to prepare nurses to work in tropical settings. 


\section{Background}

Sometimes called global or international health, tropical nursing includes several subspecialties, such as refugee healthcare, travel nursing, remote or wilderness medicine, and infectious disease. In many countries, it is not a distinct subspecialty; rather, it may be incorporated into other healthcare curricula such as public health or community nursing. ${ }^{2-11}$ This field has grown beyond caring for patients with tropical infections and now includes nursing practice in complex geopolitical and social contexts and settings with varied resources.

Countries in tropical regions may have limited physical or economic resources, resulting in poverty and subsequent overcrowding, malnutrition, and poor sanitation. ${ }^{12}$ This vicious cycle impairs immunity and increases patients' exposure to respiratory or gastrointestinal pathogens. ${ }^{12}$ As nurses provide 90\% of all healthcare services worldwide, they are essential for breaking this pattern.13 A tropical nursing curriculum prepares nursing students for these unique conditions and contexts

For example, infection is one of the leading causes of mortality and morbidity in the tropics. On average, approximately 5 million annual adult deaths are related to HIV, malaria, and tuberculosis, and the humanitarian, economic, and social impact is immeassurable. ${ }^{14}$ In children 
under age 5, approximately 28\% of global deaths are attributed to pneumonia, diarrhea, and malaria. ${ }^{15}$

Similarly, tropical disorders such as helminth infections, including strongyloides and schistosomiasis, may lead to significant disability. Gastrointestinal parasites cause a combination of malnutrition and anemia with significant ongoing consequences. ${ }^{12}$

Non-communicable diseases (NCDs) such as heart disease or diabetes also represent a major concern for global populations. Other factors that may lead to preventable deaths include alcohol abuse, tobacco use, unhealthy diet, and physical inactivity.16

Tropical nursing requires a foundation of clinical knowledge and skills and the ability to work in various social, cultural, economic, and environmental contexts. The core competencies include epidemiology, public health, environmental health, social justice, leadership and management, communication and cultural competency, healthcare access and equity, community assessment and intervention, health promotion and illness prevention, and research. ${ }^{1}$

\section{The DTN curriculum}

The DTN program at the Liverpool School of Tropical Medicine in the UK is one of a few courses designed for nurses and midwives planning to work in tropical settings with limited resources.17 Accredited by the Royal College of Nursing, the 
curriculum has been informed by the requirements of organizations that deploy nurses to address challenges around the world such as Médecins Sans Frontières (Doctors without Borders) and Voluntary Service Overseas. ${ }^{18}$ (See The DTN program.)

The curriculum is designed using a flipped classroom approach in which students familiarize themselves with a subject via reading or multimedia exposure before undergoing more intensive coursework. ${ }^{19}$ As such, each participant is required to complete approximately 20 hours of pre-course formative online learning to prepare for the intense, 3-week, classroombased coursework in Liverpool.20 The courses are designed to be fast-paced, challenging, and interactive to facilitate highquality learning that is informed by current knowledge and best practices. The program culminates in two summative assessments: an exam at the end of the program and a written assignment submitted 3 weeks after completion. Student participation is a pillar of the curriculum, which includes narrative and interactive discussions.

Using a combination format of concentrated contact time and flexible self-study makes the program accessible to participants who may be engaged in professional practice concurrently. It also fosters the development of independent, reflective approaches that enable graduates to continue learning after the completion of their DTN. A spirals of inquiry framework underpins the design of the curriculum and 
empowers students by encouraging informed choices and building confidence. ${ }^{21}$

The program equips nurses with knowledge and practical skills relevant to practice in low- and middle-income countries in both the humanitarian and development sphere. The course work is drawn from multiple sources, including published research, Sphere standards, World Health Organization recommendations, and disease-focused literature to relate theory to practical application

Nurses from around the world receive education in lab work, maternal and pediatric health, sexual health, mental health, infectious diseases, neglected tropical diseases, and NCDs. ${ }^{18}$ The curriculum also has a strong epidemiologic underpinning to help nurses understand the global burden of diseases, conditions, and health problems. Additionally, professional topics such as governance and ethics, leadership, and change agency are addressed to mirror the identified competencies of working in global health.1,18

Travel, immigration, and other social, economic, political, or environmental factors that affect health are each addressed. Context is key, and developing an understanding of these dynamics contributes to positive, mutually beneficial collaborations. As poverty, overcrowding, climate change, and access to clean water and sanitation all represent significant determinants of health, a tropical nursing background prepares nurses to identify and disrupt these cycles. 
Firmly rooted in the belief that all people have a right to healthcare, the curriculum addresses the effects of globalization and health policy on the delivery and evolution of healthcare, as well as the effect of legal systems on the just distribution of resources. It also acknowledges the global disparities in availability, accessibility, affordability, and quality of healthcare to prepare nurses to foster empowerment and the creation of sustainable, bidirectional programs and partnerships. Similarly, students are offered an introduction to key players in global health governance and become well-versed in the effects of nongovernment organizations (NGOs) and multi-agency policy making •

\section{In the field}

The DTN program prepares nurses to work with global partners in various roles to contribute to the development of institutions and individuals in different settings. Key areas of work for these nurses may include research, education, clinical care, health interventions, policy development, and technology exchange to strengthen health systems. ${ }^{22,23}$ They partner with agencies and organizations such as academic institutions, governments, and NGOs such as international oversight organizations and charitable foundations, which may provide direct healthcare as well as advocacy, policy, and science services.20 
The DTN program prepares nurses to work ethically, responsibly, and with sensitivity and respect for the history, values, and culture of the communities served. Partnerships are formed to benefit all parties, including patients, institutions, and countries. By applying the guiding principles of educational initiatives such as the DTN program, nurses can help facilitate global change to reach the world's most vulnerable communities.

\section{REFERENCES}

1. Clark M, Raffray M, Hendricks K, Gagnon AJ. Global and public health core competencies for nursing education: a systematic review of essential competencies. Nurse Educ Today. 2016;40:173-180.

2. Ablah E, Biberman DA, Weist EM, et al. Improving global health education: development of a global health competency model. Am J Trop Med Hyg. 2014;90(3):560-565.

3. Taylor S. 'Global health': meaning what? BMJ Glob Health. 2018;3(2):e000843.

4. Sheikh K, Schneider H, Agyepong IA, Lehmann U, Gilson L. Boundary-spanning: reflections on the practices and principles of global health. BMJ Glob Health. 2016;1(1):e00058.

5. Frenk J, Gómez-Dantés O, Moon S. From sovereignty to solidarity: a renewed concept of global health for an era of complex interdependence. Lancet. 2014;383(9911):94-97.

6. Martin K, Mullan Z, Horton R. Overcoming the research to policy gap. Lancet Glob Health. 2019;7(suppl 1):S1-S2.

7. Adams V, Behague D, Caduff C, Löwy I, Ortega F. Re-imagining global health through social medicine. Glob Public Health. 2019;14(10):1383-1400.

8. Adams LV, Wagner CM, Nutt CT, Binagwaho A. The future of global health education: training for equity in global health. BMC Med Educ. 2016;16(1):296 
9. Velji A, Bryant JH. Global health: evolving meanings. Infect Dis Clin North Am. 2011;25(2):299-309.

10. Koplan JP, Bond TC, Merson MH, et al. Towards a common definition of global health. Lancet. 2009;373(9679):19931995.

11. Jogerst K, Callender B, Adams V, et al. Identifying interprofessional global health competencies for 21 st-century health professionals. Ann Glob Health. 2015;81(2):239-247.

12. Miller A. What is tropical medicine? J Trop Dis. 2013;1(4):1000e106.

13. World Health Organization. The world health report 2008: primary health care: now more than ever. 2008. https://www.who.int/whr/2008/whr08_en.pdf

14. World Health Organization. Accelerating progress on HIV, tuberculosis, malaria, hepatitis and neglected tropical diseases. 2015. https://apps.who.int/iris/bitstream/handle/10665/204419/9789241510134_eng.pdf.

15. UNICEF. Under-five mortality. 2019. https://data.unicef.org/topic/child-survival/under-five-mortality.

16. World Health Organization. Noncommunicable diseases. 2020. www.who.int/en/news-room/factsheets/detail/noncommunicable-diseases.

17. Liverpool School of Tropical Medicine. Diploma in tropical nursing. 2020. www.lstmed.ac.uk/study/courses/diploma-intropical-nursing.

18. Liverpool School of Tropical Medicine. Diploma in Tropical Nursing. 2020. www.lstmed.ac.uk/study/courses/diplomain-tropical-nursing.

19. Brame CJ. Flipping the classroom. Vanderbilt University: Center for Teaching. 2013. https://cft.vanderbilt.edu/guidessub-pages/flipping-the-classroom.

20. Rowley N, Green J. Just-in-time teaching and peer instruction in the flipped classroom to enhance student learning. Education in Practice. 2015;2(1):14-17. 
21. Timperley H, Kaser L, Halbert J. Seminar series 234: a framework for transforming learning in schools: innovation and the spiral of inquiry. Centre for Strategic Education. 2014.

https://teachingcouncil.nz/sites/default/files/49.\%20Spiral\%20of\%20Inquiry\%20Paper\%20-

\%20Timperley\%20Kaser\%20Halbert.pdf.

22. Steenhoff AP, Crouse HL, Lukolyo H, et al. Partnerships for global child health. Pediatrics. 2017;140(4):pii: e20163823.

23. Merritt MG Jr, Railey CJ, Levin SA, Crone RK. Involvement abroad of U.S. academic health centers and major teaching hospitals: the developing landscape. Acad Med. 2008;83(6):541-549.

Alexis Schmid is an ED nurse and Maggie Ryan Endowed Global Health Fellow at Boston Children's Hospital in Boston, Mass., as well as a nurse for the Department of Health and Human Services' National Disaster Medical System. Frances Wood is the director of studies at the Liverpool School of Tropical Medicine in Liverpool, UK.

The authors have disclosed no financial relationships related to this article 